\title{
Plasma amino acids and neopterin in healthy persons with Down's syndrome
}

\author{
A. W. Coppus ${ }^{1,2}$, D. Fekkes ${ }^{3,5}$, W. M. A. Verhoeven $^{4,5}$, S. Tuinier ${ }^{4}$, J. I. M. Egger $^{4,6}$, C. M. van Duijn ${ }^{2}$ \\ ${ }^{1}$ Centre for Intellectual Disabilities Dichterbij, Gennep, The Netherlands \\ ${ }^{2}$ Department of Epidemiology and Biostatistics, Erasmus University Medical Centre, Rotterdam, The Netherlands \\ ${ }^{3}$ Department of Neuroscience, Erasmus University Medical Centre, Rotterdam, The Netherlands \\ ${ }^{4}$ Vincent van Gogh Institute for Psychiatry, Venray, The Netherlands \\ ${ }^{5}$ Department of Psychiatry, Erasmus University Medical Centre, Rotterdam, The Netherlands \\ ${ }^{6}$ Department of Clinical Psychology and Personality, Radboud University, Nijmegen, The Netherlands
}

Received: November 24, 2006 / Accepted: February 4, 2007 / Published online: March 31, 2007

(C) Springer-Verlag 2007

\begin{abstract}
Summary In persons with Down's syndrome (DS) immunological abnormalities as well as hypothyroidism and Alzheimer type dementia are frequently observed. In addition, the activity of the enzyme cystathionine beta-synthase (CBS) is over-expressed which results in an altered homocysteine metabolism.

In the present study, 48 older healthy DS persons without signs of dementia, psychiatric or somatic comorbidity and free of medication were analyzed for plasma levels of amino acids, neopterin and monoaminergic metabolites. Data were compared with those obtained from age and sex matched healthy controls.

It was found that the spectrum of amino acids showed widespread differences in that levels of nearly all essential amino acids were lower in DS patients as compared to healthy controls. In addition, a significantly lower methionine and higher taurine concentration were observed which is in accordance with a disturbed homocysteine metabolism. With respect to the monoamine metabolites, the concentration of 5-hydroxyindoleacetic acid was not altered whereas that of homovanillic acid was significantly increased. Finally, the concentration of the immune activation marker neopterin was increased in persons with DS.

It is concluded that healthy DS persons of older age show extensive biochemical abnormalities suggesting a compromised homocysteine metabolism, an activated cell-mediated immune response and an enhanced turnover of dopamine.
\end{abstract}

Keywords: Down's syndrome, amino acids, neopterin, dopamine

\section{Introduction}

Down's syndrome (DS) or trisomy 21 is the most common form of intellectual disability with an overall prevalence of $1.42 / 1000$ that increases significantly with maternal

Correspondence: Prof. Dr. W. M. A. Verhoeven, Vincent van Gogh Institute for Psychiatry, Stationsweg 46, 5803 AC Venray, The Netherlands

e-mail: wverhoeven@vvgi.nl age (Bray et al., 1998). Immunological abnormalities like functional impairments in fagocytes with low chemotactic ability as well as the depressed production of cytokines are intrinsic to the chromosomal disorder and result in an increased morbidity and mortality from infectious diseases (Ugazio et al., 1990). In addition, DS is associated with hypothyroidism in $20-40 \%$ of the patients and with neuropsychiatric disorders of which depression and Alzheimer-type dementia are the most frequent (Lovell and Reiss, 1993; Prasher, 1999; Bush and Beail, 2004).

Since the activity of the enzyme cystathionine $\beta$-synthase (CBS), which is encoded on chromosome 21 (21q22.3), is associated with the level of intelligence and with neuropsychiatric disorders (Abbott et al., 1987; Barbaux et al., 2000), the concentration of CBS was recently investigated in postmortem brains of DS persons (Ichinohe et al., 2005). It was found that the concentration of CBS was three times higher as compared to brain levels of normal individuals. CBS catalyzes the conversion of homocysteine and serine into cystathionine. The latter dipeptide is further metabolized into the amino acids cysteine and eventually to taurine. In humans, the sole source of homocysteine is through dietary intake of the essential amino acid methionine (Selhub et al., 1999; Ward et al., 2000).

Thus, the over-expression of CBS in persons with DS may alter homocysteine metabolism resulting in a metabolic imbalance such that folate-dependent resynthesis of methionine is compromised, and may be in favour of the transsulfuration pathway, leading eventually to increased 
levels of taurine (Huxtable, 1992). Due to the dosage effect of CBS, a decrease in plasma concentration of serine was found in DS persons. In addition, an increase in plasma lysine, which was explained by generalized premature aging in DS, was observed (Mircher et al., 1997).

Another amino acid abnormality is a decrease of systemic glutamate uptake as assessed by measuring glutamate uptake in platelets and fibroblasts from DS persons (Begni et al., 2003). The authors suggest the use of this peripheral model as a biochemical ex vivo marker of a central glutamatergic dysfunction. Excessive glutamatergic stimulation as a consequence of glutamate uptake deficits could be responsible for neuronal suffering, excitoxicity and cell death, and may play a key role in the pathophysiology of neuropsychiatric disorders (review: Van der Heijden et al., 2004).

Apart from the abovementioned amino acid abnormalities, impaired immunological function in DS persons results in increased serum neopterin levels (Mehta et al., 2005). Neopterin is not only an immune activator for the cell-mediated immune response, but also induces or enhances cytotoxicity and exhibits antioxidant properties (Hamerlinck, 1999). This observation is consistent with the increased susceptibility of DS persons to bacterial and viral infections (Cossarizza et al., 1990).

No studies have been reported on the measurement of peripheral precursors or metabolites of the neurotransmitters serotonin and dopamine in DS. Since serotonin is involved in brain growth and maturation, and experimentally induced high dopamine turnover may give rise to toxic metabolites and neurodegeneration (Ogawa et al., 1993; Alexander et al., 1997; Kupsch et al., 2001), measurement of peripheral correlates of central serotonin and dopamine metabolism is also warranted. Since at least $40 \%$ of circulating homovanillic acid (HVA) originates form the brain, the plasma HVA concentration is thought to be a fairly good indicator of the changes in dopamine metabolism in the brain (Kendler et al., 1982). In addition, plasma 5-hydroxyindoleacetic acid (5-HIAA) is suggested to be an indicator of brain serotonergic activity (Meltzer, 1989).

The present study was designed to investigate peripheral parameters that reflect changes in homocysteine metabolism, immune function and monoaminergic neurotransmission in a group older non-demented healthy persons with DS. To this end, especially the sulphur containing amino acids methionine and taurine as well as serine, glycine, glutamate, lysine, tryptophan and the other large neutral amino acids (LNAA) were measured. The ratio of tryptophan to LNAA is a fairly good indicator of central serotonin synthesis. Concentrations of the dopamine and serotonin metabolites HVA and 5-HIAA were determined as well as the levels of the immune activation marker neopterin.

\section{Materials and methods}

\section{Subjects}

Over a period of 4 years a community based sample of 505 DS persons aged 45 year and older from the Southern and the South-Western parts of the Netherlands was collected. The study protocol was approved by the Medical Ethetical Committee of the Erasmus University Medical Centre in Rotterdam, The Netherlands (protocol number: MEC 185.974/ 1999/202). In addition, the ethical committee of the local institutions provided approval. Written informed consent was obtained from the legal representatives. Details of the study population and the used screening instruments are presented elsewhere (Coppus et al., 2006).

For the present study persons were excluded in case of any relevant somatic comorbidity, including hypothyroidism and epilepsy, or the presence of a depressive disorder and signs of dementia. All persons were free of medication, including the use of folic acid, and did not smoke. The study group comprised 48 persons with DS (female: 11; male: 37; mean age: $50 \pm 4.8$ years) of whom 2 had to be excluded because of laboratory problems, and was compared to a group of 48 age and sex matched healthy controls (female: 16 ; male: 32 ; mean age: $50.2 \pm 9.1$ years).

\section{Biochemical analyses}

Plasma amino acids are analyzed by high-performance liquid chromatography (HPLC) using pre-column derivatization with o-phthaldialdehyde (Fekkes et al., 1995). The tryptophan-ratio (Trp-ratio) is calculated by dividing the total tryptophan level by the sum of the other large neutral amino acids (LNAA), i.e. valine, isoleucine, leucine, tyrosine and phenylalanine, which compete for the transport of tryptophan through the bloodbrain barrier. The tyrosine-ratio (Tyr-ratio) is calculated in the same manner by substituting tryptophan for tyrosine. The concentrations of the monoamine metabolites 5-HIAA and HVA are analyzed by HPLC and electrochemical detection (Fekkes et al., 1997). The concentration of neopterin in plasma is determined as previously described (Hoekstra et al., 2001).

\section{Statistical analyses}

For statistical comparisons between persons with DS and controls, the unpaired $t$-test was used because all data sets showed a normal distribution. Normality of the distribution was tested with the Kolmogorov-Smirnov test. A value of $p<0.05$ was considered to be statistically significant. In case of finding statistically significant values for biochemical parameters, discriminant analysis was performed in order to assess the potential for further differentiating DS persons from controls, and to establish their relative contribution to the group difference.

\section{Results}

As can be inferred from Table 1, the concentrations of methionine, glutamate and all LNAA are significantly decreased in the DS group as compared to the control group. Of the LNAA, tryptophan shows the lowest significance. The concentrations of taurine and glycine are significantly increased in DS persons as compared to controls, whereas the level of glutamate is significantly decreased. In addi- 
Table 1. Plasma levels (mean $\pm S D$ ) of biochemical parameters in DS persons and controls

\begin{tabular}{|c|c|c|c|}
\hline Biochemical parameter & DS patients (n) & Healthy controls (n) & Significance \\
\hline Tryptophan $(\mu \mathrm{mol} / 1)$ & $47.1 \pm 6.1(46)$ & $50.4 \pm 9.0(48)$ & $p=0.040$ \\
\hline Tyrosine $(\mu \mathrm{mol} / 1)$ & $61.9 \pm 12.6(46)$ & $71.0 \pm 17.3$ & $p=0.004$ \\
\hline Valine $(\mu \mathrm{mol} / 1)$ & $226.5 \pm 42.8(46)$ & $286.2 \pm 59.7(48)$ & $p<0.000$ \\
\hline Phenylalanine $(\mu \mathrm{mol} / 1)$ & $58.0 \pm 8.5(46)$ & $63.1 \pm 10.0$ & $p=0.010$ \\
\hline Isoleucine $(\mu \mathrm{mol} / 1)$ & $61.2 \pm 11.7(46)$ & $82.7 \pm 24.1(48)$ & $p<0.000$ \\
\hline Leucine $(\mu \mathrm{mol} / 1)$ & $122.6 \pm 20.9(46)$ & $148.5 \pm 31.8$ & $p<0.000$ \\
\hline Methionine $(\mu \mathrm{mol} / 1)$ & $25.6 \pm 4.7(46)$ & $32.0 \pm 6.5(48)$ & $p<0.000$ \\
\hline Taurine $(\mu \mathrm{mol} / 1)$ & $53.9 \pm 11.8(46)$ & $42.9 \pm 7.6(48)$ & $p<0.000$ \\
\hline Serine $(\mu \mathrm{mol} / 1)$ & $103.7 \pm 17.3(46)$ & $109.8 \pm 19.1(48)$ & $p=0.106$ \\
\hline Lysine $(\mu \mathrm{mol} / 1)$ & $199.3 \pm 31.8(46)$ & $186.3 \pm 35.7(48)$ & $p=0.065$ \\
\hline Glycine $(\mu \mathrm{mol} / 1)$ & $244.6 \pm 48.7(46)$ & $213.0 \pm 43.5(48)$ & $p=0.001$ \\
\hline Glutamate $(\mu \mathrm{mol} / 1)$ & $37.4 \pm 22.5(46)$ & $47.7 \pm 20.3(48)$ & $p=0.021$ \\
\hline Trp-ratio & $9.0 \pm 1.5(46)$ & $7.9 \pm 1.5(48)$ & $p<0.000$ \\
\hline Tyr-ratio & $12.2 \pm 3.3(46)$ & $11.3 \pm 2.1$ & $p=0.113$ \\
\hline Neopterin (nmol/1) & $20.4 \pm 5.8(43)$ & $17.4 \pm 3.7(28)$ & $p=0.008$ \\
\hline HVA $(\mathrm{nmol} / 1)^{\mathrm{a}}$ & $64.1 \pm 16.5(45)$ & $53.2 \pm 12.9(41)$ & $p=0.001$ \\
\hline 5-HIAA $(\mathrm{nmol} / 1)^{\mathrm{b}}$ & $43.5 \pm 9.0(45)$ & $41.5 \pm 12.9(42)$ & $p=0.405$ \\
\hline
\end{tabular}

a $H V A$ Homovanillic acid.

b 5-HIAA 5-Hydroxyindoleacetic acid.

tion, the Trp-ratio but not the Tyr-ratio, is significantly higher in the DS group compared to the controls.

With respect to neopterin, values in the DS group are significantly increased as compared to the control group. Furthermore, plasma HVA concentrations are significantly higher in the DS group, whereas no differences are found regarding 5-HIAA concentrations.

Finally, discriminant analysis (stepwise method) of the biochemical parameters with $p$-values $<0.001$ (valine, isoleucine, leucine, methionine, taurine and Trp-ratio) results in a discriminant function with valine, methionine and taurine as major predictors. Classification results are good: $84.8 \%$ of the DS persons were correctly classified as were $83.3 \%$ of the controls. As a whole $16 \%$ was wrongly classified.

\section{Discussion}

In the present study biochemical parameters related to neurotransmission and immunological function were investigated in a group of older persons with Down's syndrome. It was found that the spectrum of amino acids shows widespread differences in the DS group as compared to controls. More specific, the amino acids valine, methionine and taurine were demonstrated to differentiate persons with DS from controls. Nearly all values of amino acids are lower in the DS group, which cannot be explained from dietary effects since all persons were provided with well balanced meals. Besides, Ciaccio et al. (2003) reported that dietary measures over one year have an only marginal influence on the plasma concentration of amino acids in children with DS.
With respect to the CBS-related parameters, plasma methionine was found to be significantly lower, while taurine was higher. In addition, plasma serine was slightly decreased in DS persons. These observations are in accordance with an over-expression of the CBS-gene in DS (Chadefaux et al., 1985; Progribna et al., 2001; review: Chango et al., 2002) and are also in line with results concerning serine and taurine plasma concentrations as reported by Mircher et al. (1997). Although homocysteine was unfortunately not measured in this primarily epidemiological study, these data corroborate an altered homocysteine metabolism in persons with DS and are as such in line with the lowered plasma concentration of homocysteine reported by Pogribna et al. (2001). Other investigators, however, reported increased concentrations of homocysteine (Brattstrom et al., 1989; Guéant et al., 2005). As reviewed by Townsend et al. (2004), the sulphur containing amino acids methionine, homocysteine and taurine are involved in the maintenance and integrity of cellular systems by influencing cellular redox state and cellular capacity to detoxify toxic compounds, free radicals and reactive oxygen species. An imbalance of these amino acids in DS persons may indicate neuropathological changes in this group.

The increased Trp-ratio in the DS group suggests an enhanced availability of tryptophan for the synthesis of serotonin in the central nervous system. Whether central serotonergic neurotransmission is increased in DS persons cannot be concluded from this study, especially since the plasma concentration of 5-HIAA is not changed. The latter parameter, however, is only a very weak and indirect measure of central serotonergic activity (Lambert et al., 1995). 
On the other hand, plasma HVA concentrations are significantly increased, which is an indication of a higher turnover of dopamine that was reported previously also in cerebrospinal fluid studies in persons with DS (Kay et al., 1987; Schapiro et al., 1987).

Neopterin is increased in the DS group as compared to controls. This finding is in agreement with the observations by Metha et al. (2005) who additionally reported that increase of neopterin is not correlated with age and sex. High concentrations of neopterin as seen in DS is consistent with the impaired immune function that was reported in persons with DS (Nespoli et al., 1993; Park et al., 2000).

In conclusion, in the present study of persons with DS without any signs of dementia, somatic and/or neuropsychiatric comorbidity and free of any medication, extensive biochemical abnormalities are found suggesting a compromised homocysteine metabolism, an activated cellmediated immune response and an enhanced turnover of dopamine. Interestingly, a few peripheral biochemical parameters appeared to have a marked potential to differentiate between DS persons from controls.

\section{Acknowlegdments}

The authors are indebted to Mrs. A. C. C. Voskuilen-Kooijman, Mrs. E. Bogaerts-Taal and Mrs. M. van der Heide-Mulder for their skilled technical assistance.

\section{References}

Abbott MH, Folstein SE, Abbey H, Pyeritz RE (1987) Psychiatric manifestations of homocystinuria due to cystathione beta-synthase deficiency: prevalence, natural history and relationship to neurological impairment and vitamine B6-responsiveness. Am J Med Genet 26: 959-969

Alexander T, Sortwell CE, Sladek CD, Roth RH, Steece-Collier K (1997) Comparison of neurotoxicity following repeated administration of 1dopa, d-dopa and dopamine to embryonic mesencephalic dopamine neurons in cultures derived from Fish. Cell Transplant 6: 309-315

Barbaux R, Plomin R, Whitehead AS (2000) Polymorphisms of genes controlling homocysteine/folate metabolism and cognitive function. Neuroreport 11: 1133-1136

Begni B, Brighina L, Fumagalli L, Andreoni S, Castelli E, Francesconi C, Del Bo R, Bresolin N, Ferrarese C (2003) Altered glutamate uptake in peripheral tissues from Down syndrome patients. Neurosci Lett 343: $73-76$

Brattstrom L, Israelsson B, Tengborn L, Hultberg B (1989) Homocysteine, factor VII and antithrombin III in subjects with different gene dosage for cystathione beta-synthase. J Inherit Metab Dis 12: 475-482

Bray I, Wright DE, Davies C, Hook EB (1998) Joint estimation of Down syndrome risk and ascertainment rates: a meta-analysis of nine published data sets. Prenatal Diagn 18: 9-20

Bush A, Beail N (2004) Risk factors for dementia in people with Down syndrome: issues in assessment and diagnosis. Am J Ment Retard 109: 83-97
Chadefaux B, Rethore MO, Raoul O, Ceballos I, Poisonnier M, Gilgenkranz S, Allard D (1985) Cystathione beta-synthase: gene dosage effect in trisomy 21. Biochem Biophys Res Commun 128: 40-44

Chango A, Mircher C, James SJ, Rethore MO, Nicolas JP (2002) One carbon metabolism and trisomy 21: analysis of the genetic polymorphism. Ann Biol Clin (Paris) 60: 647-653

Ciaccio M, Piccione M, Giuffrè M, Macalone V, Vocca L, Bono A, Corsello G (2003) Aminoacid profile and oxidative status in children affected by Down syndrome before and after supplementary nutritional treatment. Ital J Biochem 52: 72-79

Coppus AW, Evenhuis E, Verberne GJ, Visser F, van Gool P, Eikelenboom P, van Duijn CM (2006) Dementia and mortality in persons with Down's syndrome. J Intellect Disabil Res 50: 768-777

Cossarizza A, Monti D, Montagnani G, Ortolani C, Masi M, Zannotti M, Franceschi C (1990) Precocious aging of the immune system in Down syndrome: alteration of B lymphocytes, T-lymphocyte subsets and cells with natural killer markers. Am J Med Genet Suppl 7: 213-218

Fekkes D, van Dalen A, Edelman E, Voskuilen A (1995) Validation of the determination of amino acids in plasma by high-performance liquid chromatography using automated derivatization with o-phthaldialdehyde. J Chromatogr B 669: 177-186

Fekkes D, Timmerman L, Pepplinkhuizen L (1997) Effects of clomipramine on plasma amino acids and serotonergic parameters in panic disorder and depression. Eur Neuro-psychopharmacol 7: 253-259

Guénant JL, Anello G, Bosco P, Guénant-Rodriguez RM, Romano A, Barone C, Gérard P, Romano C (2005) Homocysteine and related genetic polymorphisms in Down's syndrome IQ. J Neurol Neurosurg Psychiatry 76: 706-709

Hamerlinck FFV (1999) Neopterin: a review. Exp Dermatol 8: 167-176

Hoekstra R, van den Broek WW, Fekkes D, Bruijn JA, Mulder PGM, Pepplinkhuizen L (2001) Effect of anticonvulsive therapy on biopterin and large neutral amino acids in severe, medication-resistant depression. Psychiatry Res 103: 115-123

Huxtable RJ (1992) Physiological actions of taurine. Physiol Rev 72: $101-163$

Ichinohe A, Kanaumi T, Takashima S, Enokido Y, Nagai Y, Kimura H (2005) Cystathionine beta-synthase is enriched in the brains of Down's patients. Biochem Biophys Res Commun 338: 1547-1550

Kay AD, Schapiro MB, Riker AK, Haxby JV, Rapoport SI, Cutler NR (1987) Cerebrospinal fluid monoaminergic metabolites are elevated in adults with Down's syndrome. Ann Neurol 21: 408-411

Kendler KS, Heninger GR, Roth RH (1982) Influence of dopamine agonists on plasma and brain levels of homovanillic acid. Life Sci 30: 2063-2069

Kupsch A, Sautter J, Gotz ME, Breithaupt W, Schwarz J, Youdim MB, Riederer P, Gerlach M, Oertel WH (2001) Monoamine oxidase-inhibition and MPTP-induced neurotoxicity in the non-human primate: comparison of rasagiline (TVP 1012) with selegeline. J Neural Transm 108: 985-1009

Lambert GW, Kaye DM, Cox HS, Vaz M, Turner AG, Jennings GL, Esler MD (1995) Regional 5-hydroxyindoleacetic acid production in humans. Life Sci 57: 225-267

Lovell RW, Reiss AL (1993) Dual diagnoses. Psychiatric disorders in developmental disabilities. Pediatr Clin North Am 40: 579-592

Mehta PD, Patrick B, Dalton AJ, Patel B, Mehta SP, Pirttila T, Coyle PK (2005) Increased serum neopterin levels in adults with Down syndrome. J Neuroimmunol 164: 129-133

Meltzer HY (1989) Clinical studies on the mechanism of action of clozapine: the dopamine-serotonin hypothesis of schizophrenia. Psychopharmacology 99: S18-S27

Mircher C, Salabelle A, Peeters MA, Rabier D, Parvy P, Kamoun P, Lejeune J (1997) Variation des acides amines en fonction de l'age chez des subjects trisomiques 21. Arch Pediatr 4: 1093-1099 
Nespoli L, Burgio GR, Ugazio AG, Maccario R (1993) Immunological features of Down's syndrome: a review. J Intellect Disabil Res 37: $543-551$

Ogawa N, Edamatsu R, Mizukawa K, Asanuma M, Kohno M, Mori A (1993) Degeneration of dopaminergic neurons and free radicals. Possible participation of levodopa. Adv Neurol 60: 242-250

Park E, Alberti J, Mehta P, Dalton A, Sersen E, Schuller-Levis G (2000) Partial impairment of immune functions in peripheral blood leucocytes from aged men with Down's syndrome. Clin Immunol 95: 62-69

Pogribna M, Melnyk S, Progribny I, Chango A, Yi P, James SJ (2001) Homocysteine metabolism in children with Down syndrome: in vitro modulation. Am J Hum Genet 69: 88-95

Prasher VP (1999) Down syndrome and thyroid disorders: a review. Downs Syndr Res Pract 6: 25-42

Schapiro MB, Kay AD, May C, Ryker AK, Haxby JV, Kaufman S, Milstien S, Rapoport SI (1987) Cerebrospinal fluid monoamines in Down's syndrome adults at different ages. J Ment Defic Res 31: 259-269
Selhub J, Jacues PF, Rosenberg IH, Rogers G, Bowman BA, Gunter EW, Wright JD, Johnson CL (1999) Serum total homocysteine concentrations in the third National Health and Nutrition Examination Survey (1991-1994): population reference ranges and contribution of vitamin status to high serum concentrations. Ann Intern Med 131: 331-339

Townsend DM, Tew KD, Tapiero H (2004) Sulfur containing amino acids and human disease. Biomed Pharmacother 58: 47-55

Ugazio AG, Maccacio R, Notorangelo LD, Burgio GR (1990) Immunology of Down syndrome: a review. Am J Med Genet Suppl 7: 204-212

Van der Heijden FMMA, Tuinier S, Fekkes D, Sijben AES, Kahn RS, Verhoeven WMA (2004) Atypical antipsychotics and the relevance of glutamate and serotonin. Eur Neuropsycho-pharmacol 14: $259-265$

Ward M, McNulty H, Pentieve K, McPartlin J, Strain JJ, Weir DG, Scott JM (2000) Fluctuations in dietary methionine intake do not alter plasma homocysteine concentration in healthy men. J Nutr 130: $2253-2257$ 